\title{
KUAT TEKAN BETON DENGAN BESI TULANGAN D13
}

\author{
Oleh : \\ Rahelina Ginting \\ Universitas Darma Agung, Medan \\ E-Mail : \\ grahelina77@gmail.com
}

\begin{abstract}
The reinforced concrete structures are structures that are very reliable in their current strength and are widely used in the construction of tall buildings and other constructions. The building structure requires medium quality concrete and high quality to compensate for the greater tensile stress used to support the structural components.As there is a need to an increase the quality of concrete by adding screw iron to fresh concrete, added material of screw concrete D13 was chosen which is wellused both in plate planning and practical columns to be used as added material aimed at increasing the tensile stress of the concrete. This research aims at finding the high effect of strong and sticky between concrete and threaded reinforced. Research method used is experiment by using sample in the form cylinder in which the diameter is $15 \mathrm{~cm}$ and $30 \mathrm{~cm}$. Each specimen is 6 with variations of each 3 samples examined at 7 days and 3 other samples at 28 days where the quality of the concrete used was f'c $25 \mathrm{MPa}$ which was medium quality concrete. The tool used is Universal Test Machine (UTM) with a pull out test. The sticky strength obtained from the 1986 Nawy Method is 8.044 MPa, the Oragun Et Al Method is 8.861 MPa, the Kim Method and the 2015 Park are 17.417 MPa.
\end{abstract}

Keywords: Concrete Quality f'c 25 Mpa, Screw Concrete D13, Sticky Strength, Universal Test Machine (Utm), Pull Out Test

\section{PENDAHULUAN}

Perkembangan teknologi yang semakin maju disegala bidang, termasuk dibidang konstruksi. Dalam bidang konstruksi, material konstruksi yang paling disukai dan sering dipakai adalah beton.

Dewasa ini dalam praktek pembuatan beton, bahan tambahan (admixture) merupakan bahan yang dianggap penting. Penggunaan bahan tersebut dimaksudkan untuk memperbaiki dan menambah sifat beton sesuai dengan yang diinginkan.

Beragam jenis dan kegunaan admixture yang telah banyak dipasarkan saat ini banyak membantu para ahli konstruksi dalam mengatasi masalah-masalah dilapangan seperti, mengurangi kadar air semen dalam pembuatan beton karena semen lebih mahal dibandingkan 
material lainnya dalam pembuatan beton, dan untuk meningkatkan beton atau setidaknya dapat menyamai kekuatan beton yang menggunakan semen dan sebagainya.

Dalam ini yang akan diteliti adalah Pengujian Kekuatan Lekat (Bonding Strenght) Antara Tulangan Ulir Lurus dan Beton Dengan Mutu fc'25 MPa. Beton dengan mutu f'c $25 \mathrm{MPa}$ merupakan beton mutu sedang yang banyak digunakan pada beton struktur jalan, jembatan dan gedung dan lainlain.

\section{METODE PELAKSANAAN}

\section{Tinjauan Pustaka}

Landasan teori ini berdasarkan pengertian beton dan materi yang terkandung didalam beton tersebut

\section{Pengertian Beton}

Beton merupakan bagian dari batuan buatan yang diperoleh dengan cara mencampurkan semen, air, agregat halus dan agregat kasar serta dengan atau tanpa bahan tambahan dengan perbandingan tertentu. Campuran tersebut bila dituang ke dalam cetakan kemudian dibiarkan, maka akan mengeras seperti batuan.

\section{Beton Bertulang}

Beton bertulang adalah kombinasi dari beton dan baja, dimana baja tulangan

memberikan kekuatan tarik yang tidak dimiliki beton. Baja tulangan juga dapat memberikan tambahan kekuatan tekan pada struktur beton.

\section{Materi Pembentukan Beton}

Kualitas beton yang diinginkan dapat ditentukan dengan pemilihan bahan- bahan pembentuk beton yang baik, perhitungan proporsi yang tepat, cara pengerjaan dan perawatan beton dengan baik, serta pemilihan bahan tambah yang tepat dengan dosis optimum yang diperlukan. Bahan pembentuk beton adalah semen, agregat,air, dan biasanya dengan bahan tambah.

\section{a. Semem Portland}

Semen Portland disebut juga semen hidrolis yang dihasilkan dengan cara menghaluskan klinker yang terdiri dari silikat-silikat kalsium yang bersifat hidrolis dengan gips sebagai bahan tambahan (PUBI-1982, dalam Tjokrodimuljo, 1996).

Ada lima jenin Semen portland di tinjau dari tujuan penggunaannya yaitu:

1. Jenis I yaitu semen portland untuk penggunaan umum yang tidak memerlukan persyaratanpersyaratan khusus seperti yang disyaratkan pada jenis-jenis lain.

2. Jenis II yaitu semen portland yang dalam penggunaannya memerlukan ketahanan terhadap sulfat atau kalor hidrasi sedang.

3. Jenis III semen portland yang dalam penggunaannya memerlukan kekuatan tinggi pada tahap permulaan setelah pengikatan terjadi.

4. Jenis IV yaitu semen portland yang dalam penggunaannya memerlukan kalor hidrasi rendah.

5. Jenis $\mathrm{V}$ yaitu semen portland yang dalam penggunaanya memerlukan ketahanan tinggi terhadap sulfat.

\section{b. Agregat Kasar}

Agregat kasar adalah kerikil sebagai hasil desintegrasi alami dari batu atau berupa batu pecah yang diperoleh dari 
industri pemecah batu dan mempunyai ukuran butir antara $5 \mathrm{~mm}-40 \mathrm{~mm}$

\section{c. Agregat Halus}

Agregat halus adalah pasir alam sebgai hasil desintegrasi secara alami dari batu atau pasir yang dihasilkan oleh industri pemecah batu dan mempunyai ukuran butir terbesar $5 \mathrm{~mm}$. Menurut Tjokrodimuljo (1996), agregat halus adalah agregat yang berbutir kecil (antara $0,15 \mathrm{~mm}$ dan $5 \mathrm{~mm}$ ). Agregat halus sering disebut dengan pasir, baik berupa pasir alami yang diperoleh langsung dari sungai atau tanah galian maupun hasil pemecahan batu.

Syarat - syarat agregat halus (pasir) sebagai bahan material pembuatan beton sesuai dengan ASTM C 33 adalah:

1. Material dari bahan alami dengan kekasaran permukaan yang optimal sehingga kuat tekan beton besar.

2. Butiran tajam, keras, kekal (durable) dan tidak bereaksi dengan material beton lainnya.

3. Berat jenis agregat tinggi yang berarti agregat padat sehingga beton yang dihasilkan padat dan awet.

4. Gradasi sesuai spesifikasi dan hindari gap graded aggregate karena akan membutuhkan semen lebih banyak untuk mengisi rongga.

5. Bentuk yang baik adalah bulat, karena akan saling mengisi rongga dan jika ada bentuk yang pipih dan lonjong dibatasi maksimal $15 \%$ berat total agregat.

6. Bentuk yang baik adalah bulat, karena akan saling mengisi rongga dan jika ada bentuk yang pipih dan lonjong dibatasi maksimal $15 \%$ berat total agregat.

Untuk memperoleh hasil beton yang seragam, mutu pasir harus dikendalikan. Oleh karena itu pasir sebagai agregat halus harus memenuhi gradasi dan persyaratan yang ditentukan.

\section{d. Air}

Air merupakan salah satu bahan material penyusun beton yang penting walaupun harganya murah. Fungsi dari air untuk memicu proses kimiawi, semen tidak bisa menjadi pasta tanpa air.

Persyaratan yang harus dipenuhi oleh air yang agar dapat digunakan antara lain:

1. Tidak mengandung lumpur (benda melayang lainnya) lebih dari 2 gram/liter.

2. Tidak mengandung garam-garam yang dapat merusak beton (asam, zat organik, dsb) lebih dari 15 gram/liter.

3. Tidak mengandung klorida $(\mathrm{Cl})$ lebih dari 0,5 gram/liter.

4. Tidak mengandung senyawa sulfat lebih dari 1 gram/liter.

\section{e. Tulangan Baja}

Besi atau baja merupakan besi yang digunakan untuk penulangan konstruksi beton atau yang lebih dikenal sebagai beton bertulang. Tulangan baja dipasang di dalam cetakan sebelum beton di cor. Tegangan-tegangan yang terjadi pada baja, seperti juga tegangan yang terjadi pada beton yang telah mengeras, yaitu hanya disebabkan oleh beban yang bekerja pada struktur kecuali apabila terjadi kemungkinan timbulnya tegangan-tegangan sekunder 
seperti disebabkan oleh penyusutan atau sebab-sebab lainnya.

Di dalam setiap struktur beton bertulang, harus dapat diusahakan supaya tulangan baja dan beton dapat mengalami deformasi secara bersamaan, dengan maksud agar terdapat ikatan yang kuat di antara keduanya. Jenis baja yang digunakan untuk bahan struktur bangunan sipil adalah karbon lunak (kandungan karbon 0,3-0,59) persen. Baja karbon merupakan material yang daktail, artinya mampu mengalami deformasi besar tanpa mengalami keruntuhan. Sifat daktail baja dapat diketahui dari diagram teganganregangan (stress strain) dari hasil uji tarik maksimal.

\section{Elastisitas}

Hampir semua bahan teknik memiliki sifat tertentu yaitu elastisitas (elasticity). Apabila gaya luar menghasilkan perubahan bentuk (deformation) tidak melebihi batas tertentu, maka perubahan bentuk hilang sesudah gaya dilepas. Benda yang mengalami kerja gaya luar tetapi kembali pada bentuk semula secara utuh sesudah gaya dilepas disebut elastisitas sempurna (perfectly elastic).

Zat dari benda elastis dianggap homogen dan terbagi merata diseluruh volumenya sehingga meskipun suatu elemen kecil dipotong dari benda, elemen tersebut masih memiliki sifat fisik tertentu yang sama seperti benda itu sendiri. Contoh sederhana dari pembahasan diatas adalah isotropik (isotropic), sifat elastisitasnya dianggap sama kesemua arah.

Notasi Gaya dan Tegangan
Tegangan adalah perbandingan antara besar gaya tarik atau tekan terhadap luas permukaan benda tempatnya bekerja Ada dua jenis gaya luar yang bisa bekerja pada benda. Gaya terbagi merata sepanjang permukaan benda, seperti tekanan salah satu benda terhadap yang lain atau tekanan hidrostatis, atau disebut gaya permukaan atau (surface force). Gaya terbagi sepeanjang volume sebuah benda seperti gaya grafitasi, gaya magnetis, atau dalam kasus benda bergerak, gaya inersia yang disebut gaya benda (body force).

\section{Kuat Lekat}

Perkuatan pada beton dapat meningkatkan kekuatan tarik penampang bergantung pada keserasian (compatibility) antara kedua bahan tersebut untuk dapat memikul beban luar, dalam keadaan terbebani, elemen penguat seperti tulangan baja harus mengalami regangan atau deformasi yang sama dengan beton disekelilingnya untuk mencegah diskontinuitas atau terpisahnya kedua jenis material. Modulus elastisitas, daktilitas, dan kekuatan leleh maupun kekuatan repture tulangan harus lebih besar dari pada yang dimiliki beton agar terjadi peningkatan kapasitas penampang beton bertulang menjadi jauh lebih besar dari penampang beton sederhana (tanpa tulangan).

\section{Kuat Tekan Beton}

Kuat tekan beton merupakan besarnya beban persatuan luas. Kuat tekan beton ditentukan oleh perbandingan semen, agregat halus, agregat kasar, air dan berbagai campuran lainnya. Perbandingan air terhadap semen merupakan faktor utama dalam menentukan kuat tekan beton. 


\section{Panjang Penyaluran}

Adapun dasar utama teori panjang penyaluran yang digunakan dengan memperhitungkan suatu baja tulangan yang ditanam di dalam campuran beton pada silinder. Sebuah gaya P diberikan pada baja tulangan tersebut. Gaya ini selanjutnya akan ditahan antara baja tulangan dengan beton disekelilingnya. Tegangan lekat bekerja sepanjang baja tulangan yang tertanam di dalam massa beton, sehingga total gaya yang harus dilawan sebelum batang baja tercabut keluar dari massa beton adalah sebanding dengan luas selimut baja tulangan yang tertanam dikalikan dengan kuat lekat antara beton dengan baja tulangan.

Berdasarkan hasil dengan menggunakan rumus didapatkan besarnya tegangan lekatan antara tulangan dan beton. Selanjutnya besarnya tegangan lekatan hasil ekperimental akan dibandingkan dengan perhitungan tegangan lekatan dengan menggunakan persamaan empiris hasil penelitian yang telah dilakukan sebelumnya.

Dalam pelaksanaan penelitian ini dilakukan beberapa tahap penelitian, mulai dari pemilihan karakteristik material beton (pasir, agregat, semen, air), mix design beton, penanaman baja tulangan besi ulir D13, pengujian sampel, analisa data, dan saran dan kesimpulan dari hasil penelitian. Sebelum pembuatan benda uji dilakukan, perlu dipersiapkan dahulu material-material yang diperlukan dan alat-alat yang akan digunakan. Semua material dibawa ke dalam laboratorium. Sebelum digunakan kerikil dan pasir tersebut di jemur dahulu agar kandungan air yang terdapat dalam pasir dan kerikil menguap sampai kering. Sehingga material kerikil dan pasir yang digunakan saat pencampuran nanti dalam keadaan kering atau rendah kadar air. Peralatan yang digunakan dalam penelitian ini sudah tersedia di Laboratorium Beton Fakultas Teknik UDA Medan.

\section{HASIL DAN PEMBAHASAN}

Dalam pembuatan benda uji dibutuhkan hasil data untuk merencanakan mix design yang akan digunakan dalam pengecoran benda uji (sampel).

\section{Hasil Pengujian Analisa Gradasi Agregar Halus.}

Untuk mendapatkan mix design dibutuhkan data saringan agregat halus (pasir) sebagai panduan dalam menentukan berat agregat halus yang dibutuhkan dalam perencanaam mutu f'c $25 \mathrm{MPa}$. Berdasarkan angka saringan yang didapatkan maka digambarkanlah grafik hasil penyaringan, dimana gambar grafik inilah nantinya digunakan untuk mendapatkan perbandingan campuran beton. Berikut ini adalah tabel analisa saringan agregat halus.

Tabel 4.1 Analisa Saringan Agregat Halus

\begin{tabular}{|c|c|c|c|c|}
\hline & \multicolumn{4}{|c|}{ Agregat Halus } \\
\cline { 2 - 5 } $\begin{array}{c}\text { No } \\
\text { Ayak } \\
\text { an } \\
(\mathrm{mm})\end{array}$ & $\begin{array}{c}\text { Berat } \\
\text { tertah } \\
\text { an } \\
\text { (gram } \\
)\end{array}$ & $\begin{array}{c}\text { Berat } \\
\text { kumula } \\
\text { tif } \\
\text { tertaha } \\
\mathrm{n} \\
\text { (gram) }\end{array}$ & $\begin{array}{c}\% \\
\text { Kumula } \\
\text { tif } \\
\text { tertahan }\end{array}$ & $\begin{array}{c}\% \\
\text { Kumula } \\
\text { tif } \\
\text { Lolos }\end{array}$ \\
\hline 4 & 126 & 1874 & 6.30 & 93.70 \\
\hline 2 & 177 & 1697 & 8.85 & 84.85 \\
\hline 1 & 407 & 1290 & 20.35 & 64.50 \\
\hline 0.5 & 892 & 398 & 44.60 & 19.90 \\
\hline Pan & 398 & 0 & 19.90 & 0 \\
\hline
\end{tabular}

Sumber : Diolah dari Jurnal Teknik Sipil, 2017 
Agregat halus pada umumnya dibagi atas beberapa kelas, pembagian kelas ini berdasarkan atas nilai kehalusannya yaitu yang baik dipakai untuk campuran beton. Berdasarkan hasil pengujian di Laboratorium Universitas Darma Agung Medan. Dengan grafik hasil saringan mendekati/sesuai dengan grafik 4 pada SNI 03-2834-2000 dengan jenis agregat halus batas gradasi pasir (sedang) N0.2. Lihat gambar dibawah ini

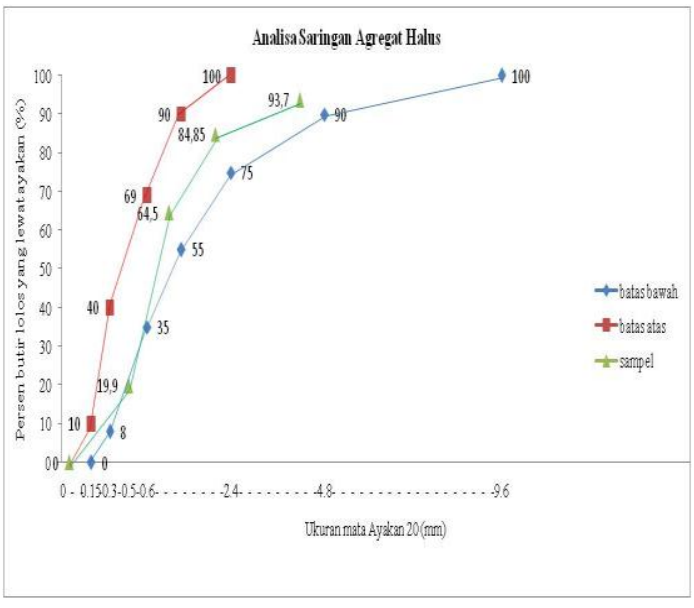

Gambar 4.1 Grafik Analisis Saringan Agregat Halus

Sumber : SNI 03-2834-2000

Dari grafik hasil saringan nomor saringan $4 \mathrm{~mm}$ menghasilkan angka komulatif lolos adalah $93.70 \%$, nomor saringan $2 \mathrm{~mm}$ menghasilkan angka komulatif lolos adalah $84.85 \%$, nomor saringan $1 \mathrm{~mm}$ menghasilkan angka komulatif lolos adalah $64.50 \%$, nomor saringan $0.5 \mathrm{~mm}$ menghasilkan angka komulatif lolos adalah $19.90 \%$ dan PAN menghasilkan angka $0 \%$. Dari gambar grafik batas atas dan grafik batas bawah saringan pada SNI 032834-2000 dengan jenis agregat halus batas gradasi pasir (sedang) N0.2. Angka hasil penyaringan menunjukkan bahwa garis sampel pada nomor $\begin{array}{llll}\text { saringan } & 0.5 & \mathrm{~mm} & \text { mengalami }\end{array}$ perpotongan pada garis kurva batas bawah hal ini terjadi karena saringan pada laboratorium di Universitas Darma Agung Medan tidak menggunakan saringan $0.15 \mathrm{~mm}$ sesuai SNI 03-28342000. Grafik yang digunakan adalah grafik 4 pada SNI 03-2834-2000 dengan jenis agregat halus batas gradasi pasir (sedang) N0.2, karena garis sampel hampir lolos sempurna/ mendekati didalam garis kurva batas atas dan batas bawah.

\section{Hasil Pengujian Analisa Gradasi Agregat Kasar}

Untuk mendapatkan mix design dibutuhkan data saringan agregat kasar (kerikil) sebagai panduan dalam menentukan berat agregat kasar yang dibutuhkan dalam perencanaan mutu f'c $25 \mathrm{MPa}$.

Tabel 4.2 Analisa Saringan Agregat Kasar

\begin{tabular}{|c|c|c|c|c|}
\hline \multirow{2}{*}{$\begin{array}{c}\text { No } \\
\text { Ayak } \\
\text { an } \\
(\mathrm{mm})\end{array}$} & $\begin{array}{c}\text { Berat } \\
\text { tertah } \\
\text { an } \\
\text { (gram } \\
\text { ) }\end{array}$ & $\begin{array}{c}\text { Berat } \\
\text { kumula } \\
\text { tif } \\
\text { tertaha } \\
\mathrm{n} \\
\text { (gram) }\end{array}$ & $\begin{array}{c}\% \\
\text { Kumula } \\
\text { tif } \\
\text { tertahan }\end{array}$ & $\begin{array}{c}\% \\
\text { Kumula } \\
\text { tif } \\
\text { Lolos }\end{array}$ \\
\hline 31,5 & 0 & 2000 & 0 & 100 \\
\hline 16 & 326 & 1676 & 16.3 & 83.70 \\
\hline 12,5 & 378 & 1296 & 18.9 & 64.80 \\
\hline 8 & 389 & 907 & 19.45 & 45.35 \\
\hline 4 & 813 & 94 & 40.65 & 4.70 \\
\hline Pan & 94 & 0 & 4.7 & 0 \\
\hline
\end{tabular}

\section{(Sumber : Diolah dari Jurnal Teknik} Sipil UDA, 2017)

Berdasarkan angka saringan yang didapatkan maka digambarkanlah grafik hasil penyaringan . dimana gambar grafik inilah nantinya digunakan untuk mendapatkan perbandingan campuran beton. Berikut ini adalah tabel analisa saringan agregat halus. 


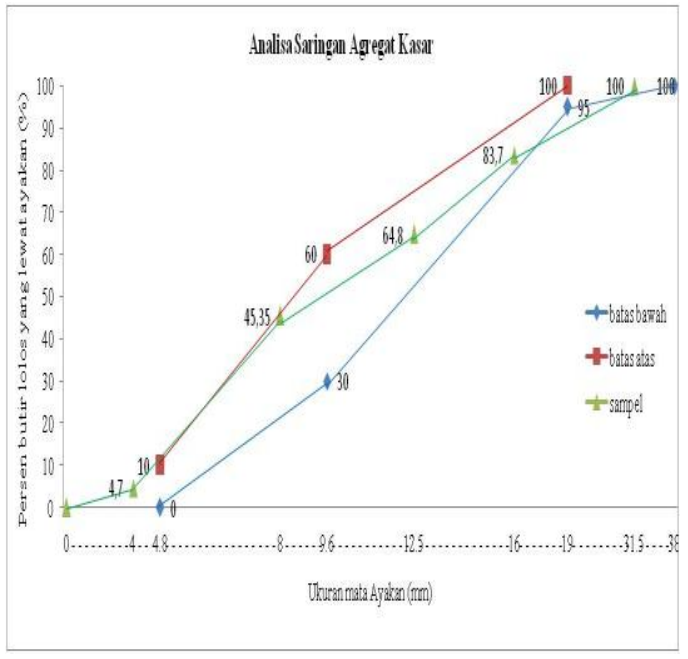

Gambar 4.2 Grafik Analisis Saringan Agregat Kasar

Sumber : SNI 03-2834-2000

Dari grafik hasil saringan nomor saringan $31.5 \mathrm{~mm}$ menghasilkan angka komulatif lolos adalah $100 \%$, nomor saringan $16 \mathrm{~mm}$ menghasilkan angka komulatif lolos adalah $83.70 \%$, nomor saringan $12.5 \mathrm{~mm}$ menghasilkan angka $64.80 \%$, nomor saringan $8 \mathrm{~mm}$ menghasilkan angka komulatif lolos adalah $45.35 \%$, nomor $4 \mathrm{~mm}$ menghasilkan angka komulatif lolos adalah $4.70 \%$ dan PAN menghasilkan angka $0 \%$. Dari gambar grafik batas atas dan grafik batas bawah saringan grafik pada SNI 03-2834-2000 dengan jenis agregat kasar batas gradasi kerikil atau koral ukuran maksimum $20 \mathrm{~mm}$. Angka hasil penyaringan menunjukkan bahwa garis sampel pada nomor saringan $16 \mathrm{~mm}$ menuju 31.5 mmmengalami perpotongan pada garis kurva batas bawah hal ini terjadi karena saringan pada laboratorium di Universitas Darma Agung Medan tidak menggunakan saringan $19 \mathrm{~mm}$ sesuai SNI 03-2834-2000. Grafik yang digunakan adalah grafik 8 pada SNI 03-2834-2000 dengan jenis agregat halus batas gradasi kerikil atau koral ukuran maksimum $20 \mathrm{~mm}$, karena garis sampel hampir lolos sempurna/ mendekati didalam garis kurva batas atas dan batas bawah

\section{Hasil Pengujian Analisa Gradasi Agregat Campuran}

Berikut adalah tabel hasil saringan agregat campuran antara kasar dan halus

Tabel 4.3 Analisa Saringan Agregat Campuran Kasar dan Halus

\begin{tabular}{|c|c|c|c|}
\hline \multirow{2}{*}{$\begin{array}{c}\text { No } \\
\text { Ayakan } \\
(\mathrm{mm})\end{array}$} & \multicolumn{3}{|c|}{ Sampel } \\
\cline { 2 - 4 } & Kurva I & Kurva II & $\begin{array}{c}\text { Agregat } \\
\text { Campuran }\end{array}$ \\
\hline 31,5 & 100 & 100 & 100 \\
\hline 16 & 62 & 86 & 89,12 \\
\hline 12,5 & 45 & 80 & 71,63 \\
\hline 8 & 38 & 76 & 49,89 \\
\hline 4 & 23 & 62 & 35,50 \\
\hline 2 & 14 & 50 & 24,25 \\
\hline 1 & 8 & 38 & 15,75 \\
\hline 0,5 & 4 & 27 & 7,00 \\
\hline 0,063 & 2 & 15 & 1,13 \\
\hline
\end{tabular}

(Sumber : Diolah dari Jurnal Teknik Sipil UDA, 2017)

Untuk mendapatkan mix design dibutuhkan data saringan agregat kasar (kerikil) dan agregat halus (pasir) dimana hasil saringan dari kedua material tersebut disaring kembali sehingga didapatlah data untuk saringan agregat campuran dalam perencanaam mutu f'c $25 \mathrm{MPa}$. Berdasarkan angka saringan yang didapatkan maka digambarkanlah grafik hasil penyaringan dimana gambar grafik inilah nantinya digunakan untuk mendapatkan perbandingan campuran beton. Berikut ini adalah tabel analisa saringan agregat halus. Berdasarkan hasil pengujian di Laboratorium Universitas Darma Agung Medan. Dengan grafik hasil saringan mendekati/sesuai dengan grafik 12 pada SNI 03-2834-2000 dengan jenis agregat 
gabungan batas gradasi agregat gabungan untuk besar butir maksimum $20 \mathrm{~mm}$

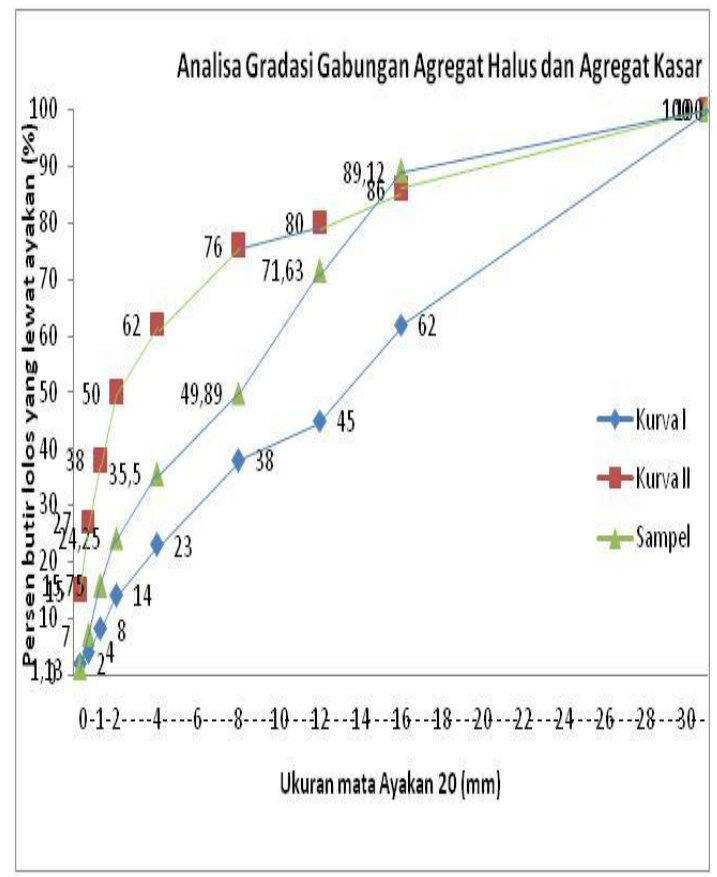

Gambar 4.3 Grafik Analisis Saringan Gradasi Campuran Agregat Halus dan Kasar

Sumber : SNI 03-2834-2000

Dari grafik hasil saringan dari nomor saringan $31.5 \mathrm{~mm}$ menghasilkan angka komulatif lolos adalah 100\% Nomor saringan $16 \mathrm{~mm}$ menghasilkan angka komulatif lolos adalah $89.12 \%$,

Nomor saringan $12.5 \mathrm{~mm}$ menghasilkan angka $71.63 \%$, Nomor saringan $8 \mathrm{~mm}$ menghasilkan angka komulatif lolos adalah $49.89 \%$, Nomor $4 \mathrm{~mm}$ menghasilkan angka komulatif lolos adalah $35.50 \%$, Nomor $2 \mathrm{~mm}$ menghasilkan angka komulatif lolos adalah $24.25 \%$, Nomor $1 \mathrm{~mm}$ menghasilkan angka komulatif lolos adalah $15.75 \%$, Nomor $0.5 \mathrm{~mm}$ menghasilkan angka komulatif lolos adalah $7.00 \%$ dan PAN menghasilkan angka $1.13 \%$. Dari gambar grafik batas atas dan grafik batas bawah saringan pada SNI 03-2834-2000 dengan jenis agregat gabungan batas gradasi agregat gabungan untuk besar butir maksimum $20 \mathrm{~mm}$. Angka hasil penyaringan menunjukkan bahwa garis sampel pada nomor saringan $16 \mathrm{~mm}$ mengalami perpotongan pada garis kurva batas atas hal ini terjadi karena saringan pada laboratorium di Universitas Darma Agung Medan tidak menggunakan saringan $19 \mathrm{~mm}$ dan $0.15 \mathrm{~mm}$ sesuai SNI 03-2834-2000. Grafik yang digunakan adalah grafik 12 pada SNI 03-2834-2000 dengan jenis agregat gabungan batas gradasi agregat gabungan untuk besar butir maksimum $20 \mathrm{~mm}$, karena garis sampel hampir lolos sempurna/ mendekati didalam garis kurva batas atas dan batas bawah

\section{Hasil Perancangan Campuran Beton ( Mix Design Concerete)}

Setelah semua data mix design didapat, dibentuklah daftar sebagai tabel berikut untuk beton $1 \mathrm{~m}^{3}$

Tabel 4.4 Rancangan Campuran Beton (Mix Design)

\begin{tabular}{|c|c|c|}
\hline No & Uraian & Nilai \\
\hline 1 & $\begin{array}{c}\text { Kuat tekan yang } \\
\text { diisyaratkan (benda } \\
\text { uji silinder) }\end{array}$ & $\begin{array}{c}25 \mathrm{MPa} \\
\text { pada } 28 \\
\text { hari }\end{array}$ \\
\hline 2 & $\begin{array}{c}\text { Standard deviasi } \\
\text { Nilai tambah } \\
\text { (margin) }\end{array}$ & - \\
\hline 4 & $\begin{array}{c}\text { Kekuatan rata-rata } \\
\text { (Fcr) }\end{array}$ & - \\
\hline 5 & $\begin{array}{c}\text { Jenis semen } \\
\text { Portland } \\
\text { tipe III }\end{array}$ \\
\hline 6 & $\begin{array}{c}\text { Jenis agregat } \\
\text { Batu } \\
\text { pecah } \\
\text { Alami }\end{array}$ \\
\hline
\end{tabular}




\begin{tabular}{|c|c|c|}
\hline 7 & $\begin{array}{c}\text { Faktor air semen } \\
\text { bebas }\end{array}$ & 0,60 \\
\hline 8 & $\begin{array}{c}\text { Faktor air } \\
\text { maksimum }\end{array}$ & 0,60 \\
\hline 9 & Slump & $\begin{array}{c}60-180 \\
\mathrm{~mm}\end{array}$ \\
\hline 10 & $\begin{array}{c}\text { Ukuran agregat } \\
\text { maksimum }\end{array}$ & $20 \mathrm{~mm}$ \\
\hline 11 & Kadar air bebas & $225 \mathrm{~kg} / \mathrm{m}^{3}$ \\
\hline 12 & Kadar semen & $375 \mathrm{~kg} / \mathrm{m}^{3}$ \\
\hline 13 & $\begin{array}{c}\text { Persen agregat halus } \\
\text { Berat Jenis relative, } \\
\text { agregat (kering } \\
\text { permukaan) }\end{array}$ & 2,70 \\
\hline 15 & Berat isi beton & $\begin{array}{c}2400 \\
\mathrm{~kg} / \mathrm{m}^{3}\end{array}$ \\
\hline 16 & $\begin{array}{c}\text { Kadar agregat } \\
\text { gabungan }\end{array}$ & $\begin{array}{c}1800 \\
\mathrm{~kg} / \mathrm{m}^{3}\end{array}$ \\
\hline 17 & Kadar agregat halus & $801 \mathrm{~kg} / \mathrm{m}^{3}$ \\
\hline 18 & Kadar agregat kasar & $999 \mathrm{~kg} / \mathrm{m}^{3}$ \\
\hline 19 & $\begin{array}{c}\text { Proporsi air yang } \\
\text { dibutuhkan }\end{array}$ & $225 \mathrm{Kg} / \mathrm{m}^{3}$ \\
\hline
\end{tabular}

Sumber : SNI 03-2834-2000

\section{Hasil Pengujian Kuat Lekat}

Dalam menghitung kuat lekat antara tulangan ulir lurus dan beton digunakan beberapa rumus antara lain :

\section{a. Metode Nawy}

Berdasarkan hasil pengujian pull out test, tegangan lekat antara tulangan ulir D13 dan beton dengan mutu f'c 25 $\mathrm{MPa}$, dengan menggunakan rumus kuat lekat metode Nawy (1986).

$\mu=\frac{P}{\pi \cdot d \cdot L d}$

dimana :

$\mathrm{P}=$ beban/ kuat tarik rata-rata $(\mathrm{N})$ $\mathrm{d}=$ diameter baja tulangan ulir (mm)

$\mathrm{Ld} \quad=$ panjang penanaman $(\mathrm{mm})$

$\mu \quad=$ kuat lekat/ tegangan lekat (Mpa)

Berdasarkan rumus diatas, didapat hasil perhitungan kuat lekat sebagai berikut:

$\mu=\frac{49.252 \mathrm{~N}}{3,14 \times 13 \mathrm{~mm} \times 150 \mathrm{~mm}}$

$\mu=\frac{49.252 \mathrm{~N}}{6.123 \mathrm{~mm} 2}$

$\mu=8,044 \mathrm{~N} / \mathrm{mm}^{2}$

$\mu=8,044 \mathrm{MPa}$

Berdasarkan perhitungan diatas didapat nilai pada tabel berikut ini :

Tabel 4.5 Hasil Pengujian Kuat Lekat Metode Nawy (1986)

\begin{tabular}{|c|c|c|c|c|c|}
\hline No & $\begin{array}{c}\text { Kate } \\
\text { gori } \\
\text { (hari } \\
\text { ) }\end{array}$ & $\begin{array}{c}\text { Panjan } \\
\text { genana } \\
\text { man } \\
(\mathrm{mm})\end{array}$ & $\begin{array}{c}\text { Diam } \\
\text { eter } \\
\text { baja } \\
(\mathrm{mm})\end{array}$ & $\begin{array}{c}\text { Kuat } \\
\text { tarik } \\
\text { rata-rata } \\
(\mathrm{N})\end{array}$ & $\begin{array}{c}\text { Tegan } \\
\text { gan } \\
\text { lekat } \\
(\mathrm{Mpa})\end{array}$ \\
\hline 1 & 7 & 150 & 13 & 49.252 & 8,044 \\
\hline 2 & 7 & 150 & 13 & 42.963 & 7,017 \\
\hline 3 & 7 & 150 & 13 & 39.146 & 6,393 \\
\hline 4 & 28 & 150 & 13 & 30.739 & 5,020 \\
\hline 5 & 28 & 150 & 13 & 32.541 & 5,300 \\
\hline 6 & 28 & 150 & 13 & 33586 & 5,485 \\
\hline
\end{tabular}

Sumber: Nawy, Beton Bertulang Suatu Pendekatan Dasar, 1986

Dari tabel 4.5 didapat nilai kuat lekat pada kategori 7 hari lebih baik dari nilai kuat lekat pada kategori 28 hari. Hal ini disebabkan oleh langkah-langkah kerja yang berbeda pada pembuatan sampel (benda uji). Dimana pada benda uji kategori 28 hari digunakan pasir sebagai penyangga besi pada bagian bawah silinder agar tidak bergerak, namun saat dilakukan rojokan besi mengalami pergeseran kebawah sehingga mengurangi panjang penyaluran dari yang direncanakan. Sementara pada benda uji dengan kategori 7 hari 
digunakan kerikil sebagai penyangga besi pada bagian bawah silinder dan besi tidak mengalami pergeseran sehingga panjang penyaluran yang direncanakan sesuai.

\section{b. Metode Oragun Et Al}

Berdasarkan metode Oragun et al (1977) tegangan lekat antara tulangan ulir D13 dan beton dengan mutu f'c 25 MPa.

Dengan menggunakan rumus kuat lekat

$\mu=0.083045 \sqrt{ } \mathrm{f}^{\prime} \mathrm{c}\left[1.2+3 \frac{c}{d b}+50 \frac{d b}{l d}\right]$

Dimana :

ld $\quad=$ Panjang penanaman $(\mathrm{mm})$

c $\quad=$ ketebalan cover beton $(\mathrm{mm})$

$\mathrm{f}^{\prime} \mathrm{c} \quad=$ Kuat tekan beton $(\mathrm{Mpa})$

$d b=$ diameter tulangan $(\mathrm{mm})$

$\mu=$ kuat lekat/ tegangan lekat (Mpa)

Berdasarkan rumus diatas, didapat hasil perhitungan kuat lekat sebagai berikut:

$\mu=0.083045 \sqrt{ } 25 \mathrm{MPa}\left[1.2+3 \frac{68.5 \mathrm{~mm}}{13 \mathrm{~mm}}\right.$

$\left.+50 \frac{13 \mathrm{~mm}}{150 \mathrm{~mm}}\right]$

$\mu=0.083045$ (5) $\mathrm{MPa}[1.2+15.807+$

4.333 ]

$\mu=0.083045$ (5) $\mathrm{MPa}[21,34]$

$\mu=8,8613 \mathrm{MPa}$

Tabel 4.6 Hasil Pengujian Kuat Lekat

Metode Oragun Et Al (1997)

\begin{tabular}{|c|c|c|c|c|}
\hline $\begin{array}{c}\text { Panjang } \\
\mathrm{n}(\mathrm{mm})\end{array}$ & $\begin{array}{c}\text { Dia } \\
\text { mete } \\
\mathrm{r} \\
\text { baja } \\
(\mathrm{mm} \\
)\end{array}$ & $\begin{array}{c}\text { Tebal } \\
\text { selimut } \\
\text { beton } \\
(\mathrm{mm})\end{array}$ & $\begin{array}{c}\text { Kuat } \\
\text { Tekan } \\
(\mathrm{MPa})\end{array}$ & $\begin{array}{c}\text { Tegang } \\
\text { an lekat } \\
\text { (Mpa) }\end{array}$ \\
\hline 150 & 13 & 68,5 & 25 & 8,861 \\
\hline
\end{tabular}

Sumber : Metode Oragun Et Al,1997

Dari tabel 4.6 dengan nilai didapat nilai yang hampir sama dengan nilai yang didapat dari metode Nawy (1986) yakni
$8 \mathrm{MPa}$. Hal ini membuktikan rumus yang digunakan oleh oragun et al (1997) dan Nawy (1986) cukup mendekati. Adapun faktor yang digunakan dalam rumus oragun et al adalah cover (selimut) beton sebagai faktor tambahan dalam menghitung kuat lekat besi dan beton.

\section{c. Metode Kim dan Park}

Berdasarkan metode Kim dan Park (2015) tegangan lekat antara tulangan ulir D13 dan beton dengan mutu f'c 25 $\mathrm{MPa}$, dengan menggunakan rumus kuat lekat

$$
\mu=\sqrt{ } f^{\prime} c\left[2.07+0.20 \frac{C m i n}{d b}+4.15 \frac{d b}{l d}\right]
$$

Dimana :

ld = Panjang penanaman $(\mathrm{mm})$

$\mathrm{f}^{\prime} \mathrm{c} \quad=$ Kuat tekan beton $(\mathrm{Mpa})$

$d b \quad=$ diameter tulangan $(\mathrm{mm})$

$\mu \quad=$ kuat lekat/ tegangan lekat (Mpa)

Cmin $=$ Cover beton minimum $(\mathrm{mm})$

Berdasarkan rumus diatas, didapat hasil perhitungan kuat lekat sebagai berikut:

$\mu=\sqrt{ } 25 \mathrm{MPa}\left[2.07+0.20 \frac{68,5 \mathrm{~mm}}{13 \mathrm{~mm}}+\right.$ $4.15 \frac{13 \mathrm{~mm}}{150 \mathrm{~mm}}$ ]

$\mu=5 \mathrm{MPa}[2.07+1.053+0.359]$

$\mu=5 \mathrm{MPa}[3.482]$

$\mu=17,417 \mathrm{MPa}$

Berdasarkan perhitungan diatas didapat nilai pada tabel berikut ini : 
Tabel 4.7 Hasil Pengujian Kuat Lekat

Metode Kim dan Park (2015)

\begin{tabular}{|c|c|c|c|c|}
\hline $\begin{array}{c}\text { Panjang } \\
\text { Penanam } \\
\text { an }(\mathrm{mm})\end{array}$ & $\begin{array}{c}\text { Diam } \\
\text { eter } \\
\text { baja } \\
(\mathrm{mm})\end{array}$ & $\begin{array}{c}\text { Tebal } \\
\text { selimut } \\
\text { beton } \\
(\mathrm{mm})\end{array}$ & $\begin{array}{c}\text { Kuat } \\
\text { tekan } \\
(\mathrm{MPa})\end{array}$ & $\begin{array}{c}\text { Tegan } \\
\text { gan } \\
\text { lekat } \\
\text { (Mpa) }\end{array}$ \\
\hline 150 & 13 & 68.5 & 25 & 17,417 \\
\hline
\end{tabular}

Sumber : Metode Kim dan Park, 2015

Dari tabel 4.7 didapat nilai kuat lekat yang cukup tinggi, namun ini dikarenakan rumus Kim dan Park (2015) menggunakan sampel (benda uji) tidak semen portland yang biasa digunakan sehari-hari. Semen yang digunakan dalam pengujian sampel (benda uji) adalah geopolimer, sehingga hasil perhitungan berbeda jauh dari metode Nawy (1986) dan Oragun Et Al (1997. Faktor semen mempengaruhi koefisien yang digunakan dalam rumus Kim dan Park (2015).

\section{KESIMPULAN DAN SARAN}

\section{Kesimpulan}

Berdasarkan hasil penelitian tentang perancangan kuat lekat antara beton dan tulangan ulir dengan pengujian pull out test (pencabutan keluar) maka dapat disimpulkan bahwa

1. Grafik hasil saringan agregat halus. Hasil saringan mendekati/sesuai dengan grafik 4 pada SNI 03-2834-2000 dengan jenis agregat halus batas gradasi pasir (sedang) N0.2.

2. Grafik hasil saringan agregat kasar. Hasil saringan mendekati/sesuai dengan grafik 8 pada SNI 03-2834-2000 dengan jenis agregat kasar batas gradasi kerikil atau koral ukuran maksimum $20 \mathrm{~mm}$.

3. Grafik hasil saringan agregat campuran. Hasil saringan mendekati/sesuai dengan grafik 11 pada SNI 03-2834-2000 dengan jenis agregat campuran batas gradasi agregat untuk besar butir maksimum $20 \mathrm{~mm}$.

Kerusakan (kehancuran) beton uji terjadi karena dimensi beton uji terlalu kecil untuk besi ulir D13.

4. Alat yang digunakan adalah Universal Test Machine (UTM) dalam pengujian pull out test (pencabutan keluar).

5. Kerusakan (retak) yang terjadi akibat kuat tarik beton lebih rendah dari dari kuat lekat tulangan ulir terhadap beton ( kuat tarik beton 10-15 \% dari kuat tekan beton)

6. Sampel 28 hari menggunakan pasir sebagai penopang tulangan ulir pada ember yang menyangga cetakan silinder, kurang maksimal menopang berat tulangan ulir D13. Sehingga tulangan mengalami penurunan saat dirojok.

7. Sampel 7 hari menggunakan kerikil sebagai penopang tulangan ulir pada ember yang menyangga cetakan silinder, lebih kokoh dalam menopang tulangan ulir D13 dari akibat penurunan saat di rojok.

8. Pemodelan dalam pengujian pull out test (pencabutan keluar) mengakibatkan beton uji terbelah ditengah.

9. Perhitungan kuat lekat dengan menggunakan metode Nawy (1986), Oragun et al (1977) hampir sama / mendekati, sedangkan Kim dan Park (2015) berbeda jauh. Dimana perbedaan ini diakibatkan oleh koefisien 
yang digunakan berdasarkan pengujian dari semen geopolimer sedangkan Nawy dan Oragun et al menggunakan semen pozzolan.

\section{Saran}

Adapun saran-saran yang dapat penulis sampaikan pada pengujian kekuatan lekat antara tulangan ulir dan beton menggunakan alat Universal Test Machine (UTM) adalah sebagai berikut

1. Ukuran saringan agregat halus dan kasar harus sesuai dengan buku perencanaan (jika menggunakan SNI 03-2834-2000 maka saringan yang digunakan harus disesuaikan).

2. Agregat untuk campuran beton dengan menggunakan material dari Binjai cukup baik (dapat digunakan). Namun dapat juga menggunakan material dari daerah lain (jika ada yang lebih baik) sebagai perbandingan.

3. Peralatan harus memadai.

4. Saat pembuatan benda uji (sampel) beton, tulangan ulir harus benar-benar diperhatikan peletakannya. Hal ini untuk memastikan angka pada panjang penyaluran sesuai semua.

5. Pemodelan harus diperbaiki, untuk mendapatkan hasil tegangan lekat yang lebih baik lagi dari yang sudah ada (besi dapat tercabut keluar dari beton uji)

6. Perlu diteliti tegangan lekat baja tulangan ulir dengan berbagai jenis tulangan ulir.

7. Perlu diteliti tegangan lekat baja tulangan ulir dengan berbagai dimensi beton.

\section{DAFTAR PUSTAKA}

ACI Committee 544. 1996. Fiber Reinforced Concrete. Michigan: ACI International Michigan.

ASTM C 33-74a. American Society For Testing and Materials. 1918. Concrete and Material Agregates (including Manual of Agregates and Consrete Testing). Philadelphia: ASTM Philadelphia.

Cement \& Concrete Institute. (2001). Fibre Reinforced Concrete, Cement \& Concrete Institute, Midrand.

Murdock, L.J dan K.M Brook

(Terjemahan : Stephanus Hendarko). 1999. Bahan dan

Praktek Beton. Jakarta: Erlangga

Tjokrodimulyo, K. 1996. Teknologi Beton, Nafitri. Yogyakarta.

Vis, 1993, Dasar-dasar perencanaan Beton Bertulang, Erlangga, Jakarata

L.J Murdock dan K.M Brook, 1991, Bahan dan Praktek Beton, Erlangga,Jakarta

Wahyudi dan Syahril A. Rahim, 1999, Metode Plastis Analisa dan Desain, Gramedia Pustaka Utama, Jakarta

Paulus, 1989 : 5 , Teknologi Beton, universitas kristen petra, surabaya

Rossena, 1954:30 , Beton Bertulang, P.T Pembangunan Djakarta, Jakarta 
Istimawan, 1994:181, Struktur Beton Bertulang, gramedia, jakarta

Winter, 1993, Perencanaan Struktur Bertulang, Pradnya Paramita, Ja karta

Nawy 1986, Beton Bertulang Suatu Pendekatan Dasar, Refika Aditama, Bandung

Anonim, 1971. Peraturan Beton Berulang Indonesia ( PBI 1971). Bandung : Departemen Pekerjaan Umum.

Standart Nasional Indonesia (SNI). 2000. Tata Cara Pembuatan Rencana Campuran Beton Normal . Jakarta : Setia Puma Inves.

Oragun et al (1977), "An Experimental of Bond Properties od Reinforcements Embedded in Concrete", International Journal of Civil,Structural, Construction and Architectural Engineering

Kim, Jee-Sang dan Jong Ho Park (2015), "An Experimental of Bond Properties od Reinforcements Embedded in Geopolymer Concrete", International Journal of Civil,Structural, Construction and Architectural Engineering Vol;9, No;2 